\title{
Characteristic, Electrical and Optical Properties of Potassium Borate (KB508.4H20) Hydrothermally Synthesised from Different Boron Sources
}

\section{FATMA TUGCE SENBERBER DUMANLI}

Yildiz Technical University

MERAL YILDIRIM OZEN

Yildiz Technical University

MIGUEL ORTEGA ASENSIO

Universidad de Valladolid

SUREYYA AYDIN YUKSEL

Yildiz Technical University

AZMI SEYHUN KIPCAK

Yildiz Technical University

Emek Moroydor Derun ( $\sim$ moroydor@gmail.com )

Yıldız Technical University https://orcid.org/0000-0002-8587-2013

\section{Research Article}

Keywords: electrical properties, potassium borate, optical properties, synthesis

Posted Date: March 17th, 2021

DOI: https://doi.org/10.21203/rs.3.rs-312150/v1

License: (1) This work is licensed under a Creative Commons Attribution 4.0 International License.

Read Full License 


\title{
Characteristic, Electrical and Optical Properties of Potassium Borate $\left(\mathrm{KB}_{5} \mathrm{O}_{8} \cdot \mathbf{4 H}_{2} \mathrm{O}\right)$ Hydrothermally Synthesised from Different Boron Sources
}

\author{
Fatma Tugce Senberber Dumanlia, ${ }^{\mathrm{a},}$, Meral Yildirim Ozen ${ }^{\mathrm{a}}$, \\ Miguel Ortega Asensio ${ }^{\mathrm{c}}$, Sureyya Aydin Yuksel ${ }^{\mathrm{d}}$, Azmi Seyhun Kipcak $^{\mathrm{a}}$, Emek Moroydor Derun $^{\mathrm{a},{ }^{*}}$, \\ ${ }^{a}$ Department of Chemical Engineering, Yildiz Technical University, Turkey \\ ${ }^{\mathrm{b}}$ Department of Civil Engineering, Nisantasi University, Turkey \\ ${ }^{\mathrm{c}}$ Department of Chemical Engineering, Universidad de Valladolid, Spain \\ ${ }^{d}$ Department of Physics, Yildiz Technical University, Turkey
}

Running title: Hydrothermally synthesis and physical properties of potassium borate

Abstract: Potassium borate was hydrothermally synthesized from various of boron minerals $\left(\mathrm{H}_{3} \mathrm{BO}_{3}\right.$, $\mathrm{B}_{2} \mathrm{O}_{3}, \mathrm{Na}_{2} \mathrm{~B}_{4} \mathrm{O}_{7} \cdot 5 \mathrm{H}_{2} \mathrm{O}$ and $\mathrm{Na}_{2} \mathrm{~B}_{4} \mathrm{O}_{7} \cdot 10 \mathrm{H}_{2} \mathrm{O}$ ) at reaction conditions of $90-60^{\circ} \mathrm{C}$ and $120-15 \mathrm{~min}$. The synthesised potassium borate was identified as "Santite $\left(\mathrm{KB}_{5} \mathrm{O}_{8} \cdot 4 \mathrm{H}_{2} \mathrm{O}\right)$ " in X-Ray diffraction (XRD) analyses results. The specific band values between $\mathrm{B}$ and $\mathrm{O}$ atoms were characterized by Fourier transform infrared and Raman Spectroscopies. Multiangular particles were generally observed in the range of $234.94 \mathrm{~nm}-3.41 \mu \mathrm{m}$. The use of different boron sources may affect the morphology. Higher reaction yields were determined in the use of boric acid $\left(\mathrm{H}_{3} \mathrm{BO}_{3}\right)$. Optical absorption of potassium borate minerals was approximately $340 \mathrm{~nm}$. AC and DC electrical properties of materials were determined by using current-voltage and capacitance voltage characteristics. Electrical resistivities of DC were found in the range of $4.17 \times 10^{8}-4.07 \times 10^{10} \Omega . \mathrm{cm}$, whereas dielectric constants of AC were between $2 \times 10^{5}$ and $2 \times 10^{6}$.

Keywords: electrical properties, potassium borate, optical properties, synthesis

\footnotetext{
* Correspondence to: Emek Moroydor Derun

Yildiz Technical University, Davutpasa Campus, Faculty of Chemical and Metallurgical Engineering, Department of Chemical Engineering, Davutpasa Street No.127, 34220 Esenler, Istanbul, Turkey

E-mail: moroydor@yildiz.edu.tr, moroydor@gmail.com, Tel: +90-212 3834776, Fax: +90-212 3834725
} 


\section{Introduction}

The metal borates are the complexes of the boron, hydrogen, oxygen and metal atoms. The common types of metal borates can be found naturally on earth or the specific types of metal borates can be prepared in micro/macro scale. Some types of metal borates have water molecules locked inside of their crystals and they are defined as borate hydrates. As being additives, both hydrated and non-hydrated forms of metal borates are used in most of industrial applications such as glass, ceramics, nuclear, spaceaviation, metallurgy, transportation, cosmetics and chemistry. Each kind of metal borate has notable features which make them preferable for different areas [1,2].

As a sub-class of metal borates, the potassium borates are important among fields such as metal refining, welding, lubricating oil additives, cement, insulation, textiles, fiberglass and as a superior non-linear optical material (NLO) against commonly used borate compounds. Potassium pentaborate $\left(\mathrm{KB}_{5} \mathrm{O}_{8} \cdot 4 \mathrm{H}_{2} \mathrm{O}\right)$ is also known as "santite" mineral. It has the orthorhombic lattice system and its crystals are at the appearance of transparent and colourless aggregates [3-6].

There are different types of prepared potassium borates in the system of $\mathrm{K}_{2} \mathrm{O}-\mathrm{B}_{2} \mathrm{O}_{3}-\mathrm{H}_{2} \mathrm{O}$. Zhang et al., obtained the $\mathrm{KB}_{5} \mathrm{O}_{7}(\mathrm{OH})_{2} \cdot \mathrm{H}_{2} \mathrm{O}$ by using the raw materials of potassium hydroxide $(\mathrm{KOH})$, boric acid $\left(\mathrm{H}_{3} \mathrm{BO}_{3}\right)$ and pyridine at $170^{\circ} \mathrm{C}$ for 7 days [7]. Salentine prepared the $\mathrm{KB}_{3} \mathrm{O}_{5} \cdot 3 \mathrm{H}_{2} \mathrm{O}$ by the liquid state synthesis of $\mathrm{K}_{2} \mathrm{~B}_{4} \mathrm{O}_{7} \cdot 4 \mathrm{H}_{2} \mathrm{O}$ and $\mathrm{KB}_{5} \mathrm{O}_{8} \cdot 4 \mathrm{H}_{2} \mathrm{O}$ [8]. Wu synthesized the $\mathrm{K}_{[}\left[\mathrm{B}_{5} \mathrm{O}_{7}(\mathrm{OH})_{2}\right]$ using the potassium nitrate $\left(\mathrm{KNO}_{3}\right)$ and $\mathrm{H}_{3} \mathrm{BO}_{3}$ at the reaction temperature $210^{\circ} \mathrm{C}$ for 3 days [9]. Wang et al., produced the $\mathrm{KB}_{3} \mathrm{O}_{4}(\mathrm{OH})_{2}$ by the hydrothermal reaction of $\mathrm{K}_{2} \mathrm{~B}_{4} \mathrm{O}_{7} \cdot 4 \mathrm{H}_{2} \mathrm{O}$, DMF and $\mathrm{H}_{2} \mathrm{O}$ at $165^{\circ} \mathrm{C}$ for 10 days [10]. Liu et al., searched the thermochemistry of the synthesized $\mathrm{K}_{2} \mathrm{~B}_{5} \mathrm{O}_{8}(\mathrm{OH}) \cdot 2 \mathrm{H}_{2} \mathrm{O}$ with using the raw materials of potassium carbonate $\left(\mathrm{K}_{2} \mathrm{CO}_{3}\right)$ and $\mathrm{H}_{3} \mathrm{BO}_{3}$ in hydrothermal conditions at the reaction temperature $170^{\circ} \mathrm{C}$ for 7 days [11]. Alicilar studied the flame retardation and smoke suppression efficiencies of potassium additives in styrene acrylic paints [12].

The determination of electrical and optical features of compound is essential for the nanophotonic devices, semiconductor materials, solar cells, laser and display applications [13-16]. The physical features of boron compounds and boron-doped materials should be comprehensively detailed. The research would like to contribute to possible use of potassium borates in the use of electronic and optic 
applications. With this purpose, the synthesized potassium borates different boron sources were chemically and physically characterized.

\section{Materials and methods}

\subsection{Raw materials preparation and characterization}

Different raw materials were used during the experiments, each of them presenting a source of boron, potassium or being need for the materials to react and lead to the formation of potassium borate. Potassium nitrate $\left(\mathrm{KNO}_{3}\right)$, with the minimum purity of $99 \%$, was purchased from MERCK Chemicals and used without pre-treatment. Boric acid $\left(\mathrm{H}_{3} \mathrm{BO}_{3}\right)$, boron oxide $\left(\mathrm{B}_{2} \mathrm{O}_{3}\right)$, tincalconite $\left(\mathrm{Na}_{2} \mathrm{~B}_{4} \mathrm{O}_{7} \cdot 5 \mathrm{H}_{2} \mathrm{O}\right)$ and borax $\left(\mathrm{Na}_{2} \mathrm{~B}_{4} \mathrm{O}_{7} \cdot 10 \mathrm{H}_{2} \mathrm{O}\right)$ were retrieved from Bandırma Boron Works (Eti Maden, Balıkesir, Turkey) at a particle size of $2 \mathrm{~mm}$ with the minimum purities of higher than $98 \%$. In order to maintain a particle sized below $75 \mu \mathrm{m}$, boron sources were ground with Retsch RM 100 (Retsch GmbH \& Co KG, Haan, Germany) agate mortar and sieved through Fritsch analysette 3 Spartan pulverisette 0 vibratory sieve-shaker (Fritsch, Idar-Oberstein, Germany).

Characterization of the raw materials were conducted by PANalytical Xpert Pro (PANalytical B.V., Almelo, The Netherlands) XRD with the generator settings of of $45 \mathrm{kV}$ and $40 \mathrm{~mA}$. In the XRD analysis $\mathrm{Cu}-\mathrm{K} \alpha\left(\lambda=1.53 \mathrm{~cm}^{-1}\right)$ radiation is used and the $2 \theta$ range is selected between of $10-90^{\circ}$.

\subsection{Synthesis procedure}

In the production of potassium borates, six different raw materials were reacted at different molar ratios, which were determined from pre-experiments were given in Table 1. For all of the sets the potassium source was used as $\mathrm{KN}\left(\mathrm{KNO}_{3}\right)$. Sodium source was used as $\mathrm{Na}(\mathrm{NaOH})$ in Set 1 and Set 2 . The boron sources were used as $\mathrm{H}\left(\mathrm{H}_{3} \mathrm{BO}_{3}\right)$ in Set 1 , Set 3 and Set 5 and $\mathrm{B}\left(\mathrm{B}_{2} \mathrm{O}_{3}\right)$ in Set 2, Set 4 and Set 6. T $\left(\mathrm{Na}_{2} \mathrm{~B}_{4} \mathrm{O}_{7} \cdot 5 \mathrm{H}_{2} \mathrm{O}\right)$ and $\mathrm{Bx}\left(\mathrm{Na}_{2} \mathrm{~B}_{4} \mathrm{O}_{7} \cdot 10 \mathrm{H}_{2} \mathrm{O}\right)$ were used as both sodium and boron sources in Set 3 , Set 4 and Set 5, Set 6, respectively. The reaction temperatures and times were determined between $90-60^{\circ} \mathrm{C}$ and 120-15 min, respectively. Expected reaction are given between (1) to (6): 


$$
\begin{aligned}
& \mathrm{KNO}_{3}(s)+\mathrm{NaOH}(s)+6 \mathrm{H}_{3} \mathrm{BO}_{3}(s)+x \mathrm{H}_{2} \mathrm{O}(l) \stackrel{\text { heat }}{\rightarrow} \\
& \mathrm{KB}_{5} \mathrm{O}_{8} \cdot 4 \mathrm{H}_{2} \mathrm{O}(a q)+\mathrm{H}_{3} \mathrm{BO}_{3}(a q)+\mathrm{NaNO}_{3}(a q)+y \mathrm{H}_{2} \mathrm{O}(l) \\
& \mathrm{KNO}_{3}(s)+\mathrm{NaOH}(s)+3.5 \mathrm{~B}_{2} \mathrm{O}_{3}(s)+x \mathrm{H}_{2} \mathrm{O}(l) \stackrel{\text { heat }}{\rightarrow} \\
& \mathrm{KB}_{5} \mathrm{O}_{8} \cdot 4 \mathrm{H}_{2} \mathrm{O}(a q)+2 \mathrm{H}_{3} \mathrm{BO}_{3}(a q)+\mathrm{NaNO}_{3}(a q)+y \mathrm{H}_{2} \mathrm{O}(l) \\
& \mathrm{KNO}_{3}(s)+1 / 2 \mathrm{Na}_{2} \mathrm{~B}_{4} \mathrm{O}_{7} .5 \mathrm{H}_{2} \mathrm{O}+4 \mathrm{H}_{3} \mathrm{BO}_{3}(s)+x \mathrm{H}_{2} \mathrm{O}(\mathrm{l}) \stackrel{\text { heat }}{\rightarrow} \\
& \mathrm{KB}_{5} \mathrm{O}_{8} \cdot 4 \mathrm{H}_{2} \mathrm{O}(a q)+\mathrm{H}_{3} \mathrm{BO}_{3}(a q)+\mathrm{NaNO}_{3}(a q)+y \mathrm{H}_{2} \mathrm{O}(\mathrm{l}) \\
& \mathrm{KNO}_{3}(s)+1 / 2 \mathrm{Na}_{2} \mathrm{~B}_{4} \mathrm{O}_{7} .5 \mathrm{H}_{2} \mathrm{O}+2 \mathrm{~B}_{2} \mathrm{O}_{3}(s)+x \mathrm{H}_{2} \mathrm{O}(l) \stackrel{\text { heat }}{\rightarrow} \\
& \mathrm{KB}_{5} \mathrm{O}_{8} \cdot 4 \mathrm{H}_{2} \mathrm{O}(a q)+\mathrm{H}_{3} \mathrm{BO}_{3}(a q)+\mathrm{NaNO}_{3}(a q)+y \mathrm{H}_{2} \mathrm{O}(\mathrm{l}) \\
& \mathrm{KNO}_{3}(s)+1 / 2 \mathrm{Na}_{2} \mathrm{~B}_{4} \mathrm{O}_{7} \cdot 10 \mathrm{H}_{2} \mathrm{O}+3 \mathrm{H}_{3} \mathrm{BO}_{3}(s)+x \mathrm{H}_{2} \mathrm{O}(\mathrm{l}) \stackrel{\text { heat }}{\rightarrow} \\
& \mathrm{KB}_{5} \mathrm{O}_{8} \cdot 4 \mathrm{H}_{2} \mathrm{O}(a q)+\mathrm{NaNO}_{3}(a q)+y \mathrm{H}_{2} \mathrm{O}(\mathrm{l}) \\
& \mathrm{KNO}_{3}(s)+1 / 2 \mathrm{Na}_{2} \mathrm{~B}_{4} \mathrm{O}_{7} .5 \mathrm{H}_{2} \mathrm{O}+5 / 2 \mathrm{~B}_{2} \mathrm{O}_{3}(s)+x \mathrm{H}_{2} \mathrm{O}(\mathrm{l}) \stackrel{\text { heat }}{\rightarrow} \\
& \mathrm{KB}_{5} \mathrm{O}_{8} \cdot 4 \mathrm{H}_{2} \mathrm{O}(a q)+\mathrm{H}_{3} \mathrm{BO}_{3}(a q)+\mathrm{NaNO}_{3}(a q)+y \mathrm{H}_{2} \mathrm{O}(l)
\end{aligned}
$$

During the synthesis $100 \mathrm{~mL}$ batch type temperature controlled glass reactor was used. Distilled water obtained from GFL 2004 (Gesellschaft für Labortechnik, Burgwedel, Germany) water purification system was used for the reaction medium. In the experiments the boron sources were added to reactor and after the determined temperature is reacted the potassium and sodium sources were added to medium. After the determined reaction time was reacted, reactor contents were placed in a glass crystallizer that the crystallizer were placed in an $40^{\circ} \mathrm{C}$ adjusted oven (Ecocell LSIS-B2V/EC55; MMM Medcenter Einrichtungen, Planegg, Germany) in order to evaporate the excess water and crystallization to occur. After the crystals formed, the sample were washed with pure ethanol to remove the unreacted raw materials and formed by product of $\mathrm{NaNO}_{3}$. Then excess ethanol were removed by putting the washed sample in an $40^{\circ} \mathrm{C}$ adjusted oven.

\subsection{Characterization of the synthesized products}

After the liquid state synthesis of potassium borates, the samples were characterised by XRD, FT-IR and Raman spectroscopy techniques. The XRD parameters used as same as in " 2.1 Raw material preparation and characterisation" except $2 \theta$ range was selected between $10-90^{\circ}$, where the characteristic peaks of potassium borates were observed. 
For the FT-IR analyses, PerkinElmer Spectrum One model FT-IR (PerkinElmer, MA, USA) with a universal attenuation total reflectance (ATR) sampling accessory that uses a diamond/ZnSe crystal is used. In the Raman analyses, Perkin Elmer Raman Station 400F (PerkinElmer, CT, USA) Raman spectrometer is used. The characteristic vibrations of both FT-IR and Raman spectra analysed at the range between $1800-650 \mathrm{~cm}^{-1}$ and $1600-250 \mathrm{~cm}^{-1}$, respectively.

The surface morphologies and particle sizes of the samples were investigated by using CamScan brand Apollo 300 field-emission SEM (CamScan, Oxford, UK) at $15 \mathrm{kV}$. The detector used was back scattering electron (BEI) and the magnification was set to 5,000.

Three parallel experiments for each formation were conducted for the santite yield calculations. $\mathrm{KNO}_{3}$ was selected as the key component (limiting reactant) and the equation used in the calculation is given below:

$$
Y_{\text {Santite }}=\frac{N_{\text {Santite }}}{\left(N_{\mathrm{KNO}_{3}}\right)_{i}-\left(N_{\mathrm{KNO}_{3}}\right)_{f}}
$$

where $Y_{\text {Santite }}$ is the yield of Santite, $N_{\text {Santite }}$ is the final formation mole of Santite, $\left(N_{K N O 3}\right)_{i}$ and $\left(N_{K N O 3}\right)_{f}$ are the moles of $\mathrm{KNO}_{3}$ initial and final, respectively.

\subsection{Electrical and optical properties}

The potassium borates powder which have the highest XRD scores were pressed under pressure of $30 \mathrm{MPa}$ into pellets with $13 \mathrm{~mm}$ diameters. Electrical resistivity of the samples was measured with current-voltage technique at room temperature using Keithley 2400 in dark with thermally evaporated gold contacts on both surfaces of pellets in high vacuum $10^{-6}$ Torr. The optical absorption spectra of the borate powders were taken by Perkin Elmer UV-vis spectrophotometer (PerkinElmer, MA, USA) at room temperature which dispersed in $\mathrm{HCl}$ solution in quartz tube. In order to determine the dielectric properties of the materials, pellets are gold coated on both surfaces using thermal evaporation technique under high vacuum to create a parallel plate capacitor structure. Dielectric measurements were performed using $\mathrm{HP} 4192 \mathrm{~A}$ impedance analyser in the frequency range 5 to $1.3 \times 10^{7} \mathrm{~Hz}$ at room temperature.

\section{Results and discussion}




\subsection{XRD Results}

According to the XRD analysis, the raw materials used and produced potassium borate results were given in Table 2. According to the Table 2, potassium source of $\mathrm{KN}$ are found as "Nitre" with powder diffraction file (pdf) no. of "00-005-0377" and boron sources of H and B are found as "Sassolite" and "Boron oxide" with pdf no of "01-073-2158" and "00-006-0297", respectively. Sodium and boron sources of $\mathrm{T}$ and $\mathrm{Bx}$ are found as "Tincalconite" and "Borax" with pdf nos of "00-007-0277" and "01075-1078", respectively. The synthesized potassium borate compound is found as "Sassolite" with pdf no. of "01-072-1688". Synthesized type of a mineral is the same as in the study of Asensio et al. (2016) [6].

The XRD scores of the synthesized compounds are given in Table 3. The XRD score is the measure of the similarity of the theoretical compound meaning that when all the peak intensities (\%) and peak locations are matched perfectly with the reference card, the XRD score of the analysed mineral is equal to $100[6,17]$.

The results of XRD analyses indicate the suitability of the hydrothermal conditions for the potassium borate synthesis. It is seen that the potassium borates are formed at different scores, in all the reaction parameters. The highest XRD scores are obtained at low reaction temperature and low reaction times. On the other hand, the changes in the reaction parameters are not affecting the crystal phase formation slightly. The highest XRD score is found as " 77 " at Set 3 with the reaction conditions of $60^{\circ} \mathrm{C}$ and $60 \mathrm{~min}$. On the other hand, in the study of Asensio et al. (2016), the highest XRD score was obtained at the reaction parameters of $60^{\circ} \mathrm{C}$ and 15 min with the value of " 74 " from the raw materials of $\mathrm{K}_{2} \mathrm{CO}_{3}$ and $\mathrm{H}_{3} \mathrm{BO}_{3}[6]$.

In the first three Sets, the highest XRD scores are obtained at the reaction parameters of $60^{\circ} \mathrm{C}$ reaction temperature and 60 min of reaction time with the values of 75, 72 and 77. At the last three Sets, the highest XRD scores are obtained at the reaction parameters of $70^{\circ} \mathrm{C}-30 \mathrm{~min}, 70^{\circ} \mathrm{C}-120 \mathrm{~min}$ and $80^{\circ} \mathrm{C}-30$ min with the values of 69,72 and 72 . These six highest XRD scored potassium borate minerals were determined as the optimum formations. The optimum formations XRD patterns are given in Figure 1. 
Figure 1. XRD patterns of the optimum potassium borate phases

In Figure 1, the characteristic peaks (h k $1\left[\mathrm{~d}_{\text {spacing }}\right]$ ) of Santite were observed at the $2 \theta$ of $14.92^{\circ}$

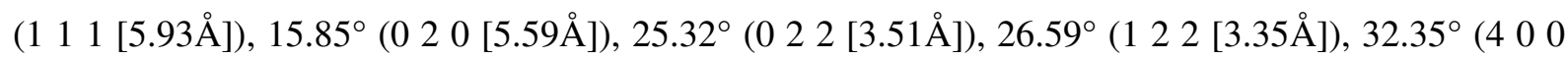
$[2.77 \AA])$ and $41.52^{\circ}(422[2.17 \AA])$. These peak locations were in god agreement with the study of Asensio et al. (2016) [6].

\subsection{FT-IR and Raman spectroscopy results}

FT-IR spectra of optimum potassium borate compounds are given in Figure 2. For each reaction Sets, the obtained FT-IR spectra of synthesized potassium borates showed similarity.

Figure 2. FT-IR spectra of selected potassium borates

The peaks which are located between $1335-1329 \mathrm{~cm}^{-1}$ are assigned to the asymmetric stretching of three coordinate boron to oxygen bands $\left[v_{\mathrm{as}}\left(\mathrm{B}_{(3)}-\mathrm{O}\right)\right]$. The peaks in the range of $1247-1245 \mathrm{~cm}^{-1}$ are attributed to the bending mode of boron-oxygen-hydrogen $[\delta(\mathrm{B}-\mathrm{O}-\mathrm{H})]$. The asymmetric stretching of four coordinate boron to oxygen bands $\left[\mathrm{vas}_{\mathrm{as}}\left(\mathrm{B}_{(4)}-\mathrm{O}\right)\right]$ are observed between $1097 \mathrm{~cm}^{-1}$ and $1021 \mathrm{~cm}^{-1}$. The bands around $915 \mathrm{~cm}^{-1}$ are related to the symmetric stretching of three coordinate boron to oxygen bands $\left[v_{\mathrm{s}}\left(\mathrm{B}_{(3)}-\mathrm{O}\right)\right]$. The absorption peaks around $781 \mathrm{~cm}^{-1}$ are due to the symmetric stretching of four coordinate boron to oxygen bands $\left[v_{\mathrm{s}}\left(\mathrm{B}_{(4)}-\mathrm{O}\right)\right]$. The presence of IR peaks between $692 \mathrm{~cm}^{-1}$ and $688 \mathrm{~cm}^{-}$ ${ }^{1}$ reveals the bending of three coordinate boron $[\delta(\mathrm{B}-\mathrm{O}-\mathrm{H})]$.

In Figure 3, Raman spectra of selected potassium borates are shown. According to Raman spectra, the bending of $v_{\text {as }}\left(B_{(4)}-O\right)$ is observed in the range of $1067-1049 \mathrm{~cm}^{-1}$, whereas the peaks at $917 \mathrm{~cm}^{-1}$ are assigned to the symmetric stretching of $v_{\mathrm{s}}\left(\mathrm{B}_{(3)}-\mathrm{O}\right)$. The Raman frequencies around $765 \mathrm{~cm}^{-1}$ belong to the symmetric stretching of $v_{\mathrm{s}}\left(\mathrm{B}_{(4)}-\mathrm{O}\right)$. The peaks at $556 \mathrm{~cm}^{-1}$ attributed to the symmetric pulse vibration frequency of the pentaborate anion $\left[\left(\mathrm{B}_{5} \mathrm{O}_{6}(\mathrm{OH})_{4}\right)^{-}\right]$. The peaks which are shown the bending of four coordinate boron $\delta\left(\mathrm{B}_{(4)}-\mathrm{O}\right)$ are seen between $510 \mathrm{~cm}^{-1}$ and $456 \mathrm{~cm}^{-1}[6,19,20]$. These findings are in 
accordance with spectral characteristics of potassium borates which are obtained in the literature studies [6].

Figure 3. Raman spectra of selected potassium borates

\subsection{SEM results}

The surface morphologies of selected potassium borate samples are given in Figure 4. According to SEM images of produced potassium borates, it is avowable that the morphology of products did not show a significant change based on precursor materials, reaction temperatures and reaction times. According to SEM images, the particle sizes of synthesized potassium borates were changed between $234.94 \mathrm{~nm}$ and $3.41 \mu \mathrm{m}$. When uniform particle size distribution were observed for lower reaction temperatures and times, especially for Set 1 , increasing reaction times and temperatures led to irregular particle morphologies.

For Set 2, the potassium borate particles had overlapped shapes when multiangular particles obtained for Set 3. In Set 4, the particle size reduced to sub-micron scales but showed tendency to agglomeration. Irregular particle size distribution and morphology existed for Set 5 and Set 6, in which overlapped layers of potassium borate were observed.

Figure 4. The surface morphologies of selected potassium borates

\subsection{Reaction yields}

Reaction yields based on the santite formation is given in Figure 5. All formations standard deviation is less than 5\%. Considering all of the sets the minimum santite yield was calculated as $76 \%$ in Set 2 at $60^{\circ} \mathrm{C}$ and 15 min reaction time. As a comparison between the reactants of $\mathrm{H}_{3} \mathrm{BO}_{3}$ and $\mathrm{B}_{2} \mathrm{O}_{3}$, highest santite yields were seen on $\mathrm{H}_{3} \mathrm{BO}_{3}$. Because $\mathrm{H}_{3} \mathrm{BO}_{3}$ is more reactive than $\mathrm{B}_{2} \mathrm{O}_{3}$, since $\mathrm{B}_{2} \mathrm{O}_{3}$ was produced from $\mathrm{H}_{3} \mathrm{BO}_{3}$, which the reaction was given below: 


$$
\mathrm{H}_{3} \mathrm{BO}_{3}+\text { heat } \rightarrow \frac{1}{2} \mathrm{~B}_{2} \mathrm{O}_{3}+\frac{3}{2} \mathrm{H}_{2} \mathrm{O}
$$

More likely for the comparison of $\mathrm{Na}_{2} \mathrm{~B}_{4} \mathrm{O}_{7} \cdot 5 \mathrm{H}_{2} \mathrm{O}$ and $\mathrm{Na}_{2} \mathrm{~B}_{4} \mathrm{O}_{7} \cdot 10 \mathrm{H}_{2} \mathrm{O}, \mathrm{Na}_{2} \mathrm{~B}_{4} \mathrm{O}_{7} \cdot 5 \mathrm{H}_{2} \mathrm{O}$ as a reactant more active than the $\mathrm{Na}_{2} \mathrm{~B}_{4} \mathrm{O}_{7} \cdot 10 \mathrm{H}_{2} \mathrm{O}$. This may be due to the boron percentages of the compounds since $\mathrm{Na}_{2} \mathrm{~B}_{4} \mathrm{O}_{7} \cdot 5 \mathrm{H}_{2} \mathrm{O}$ has more boron percentage than the $\mathrm{Na}_{2} \mathrm{~B}_{4} \mathrm{O}_{7} \cdot 10 \mathrm{H}_{2} \mathrm{O}$. As the combination of both $\mathrm{Na}_{2} \mathrm{~B}_{4} \mathrm{O}_{7} \cdot 5 \mathrm{H}_{2} \mathrm{O}$ and $\mathrm{H}_{3} \mathrm{BO}_{3}$ the highest santite yield was seen on the set of 3. Also the reactant of $\mathrm{NaOH}$ yield santite formation between $\mathrm{Na}_{2} \mathrm{~B}_{4} \mathrm{O}_{7} \cdot 5 \mathrm{H}_{2} \mathrm{O}$ and $\mathrm{Na}_{2} \mathrm{~B}_{4} \mathrm{O}_{7} \cdot 10 \mathrm{H}_{2} \mathrm{O}$.

Figure 5. Reaction yields of samples

For the reaction temperatures and times, as it is seen from the Figure 5, santite yields were increased by the increase in both reaction temperature and time. The highest santite yield was obtained as $99 \%$ at set3 at $90^{\circ} \mathrm{C}$ reaction time and 120 min reaction time. Higher santite formations were obtained than Asensio et al., 2016, which were between $84-95 \%$.

\subsection{Optical and Electrical measurement results}

The optical absorption spectra of the potassium borate powders synthesized using various boron minerals are shown in Fig. 6. The optical absorption edge was determined from extrapolation of the high-energy part of the absorption spectra and is shown in Fig. 6. The optical absorption edge of the potassium borate powders observed about $340 \mathrm{~nm}$ for SET 1 to 5 and about $480 \mathrm{~nm}$ for SET 6 .

Figure 6. The optical absorbance spectrum of potassium borates powders.

The DC current density-voltage characteristics of the potassium borates materials, which was determined using a standard technique for the samples with the highest XRD scores synthesized at from various types of boron minerals Fig.7 shows that the all potassium borate materials have high dc electrical resistance these properties valuable in terms of their ability to use materials as shielding. The 
bulk dc electrical resistivity of samples were determined in the range of $4.17 \times 10^{8}-4.07 \times 10^{10} \Omega . c m$ using the following equation.

$$
R=\rho \frac{l}{A}
$$

where $\mathrm{R}$ is the electrical resistance, $\rho$ is the self-resistivity, $\mathrm{A}$ is the area of the sample surface, and 1 is the length.

Figure 7. The DC current density-voltage characteristics of potassium borate materials synthesized using various boron minerals

Impedance spectroscopy is a widely used analysis method that provides information about the dielectric properties of materials. The dielectric properties of the materials were examined at different frequencies and at room temperature. The complex permittivity $\left(\varepsilon^{*}\right)$ is given by the following equation,

$\varepsilon^{*}=\varepsilon^{\prime}-i \varepsilon^{\prime \prime}$

where $\varepsilon^{\prime}$ is the relative permittivity or dielectric constant, $\varepsilon^{\prime \prime}$ is the dielectric loss.

The dielectric constant and loss are calculated by the following equation (8),

$\varepsilon^{\prime}=\frac{C_{p} d}{A \varepsilon_{o}}$

where $\mathrm{d}$ is the sample thickness, $\mathrm{A}$ is the surface area of the electrodes, $\varepsilon_{0}$ is the electrical permittivity of vacuum and $\mathrm{C}_{\mathrm{p}}$ is the capacitance of the sample.

Figure 8. Frequency dependence of real part dielectric constant for potassium borates samples.

Figure 8 shows the variation of the actual part of the dielectric constant depending on the frequency at room temperature. All materials showed very close dielectric constant and AC conductivity value and characteristic results. At low frequencies $\left(5-10^{2} \mathrm{~Hz}\right)$, the dielectric constant is high about $2 \times 10^{5}$ to $2 \times 10^{6}$ and decreases to about 10 with increasing frequency for all samples. 
Figure 9 shows the similarly defined AC conductivity as approximate value and change in all type potassium borate materials as a function of frequency at room temperature. As shown in Figure 9, a constant region indicating DC-like conductivity in the low frequency region was observed and it was found that the conductivity increases with frequency starting from a limit frequency. The AC conductivity value in the DC-like region for materials are about $1.7 \times 10^{-7} \mathrm{~S} / \mathrm{cm}$ and again from about $1 \mathrm{kHz}$, the exponential increasing ac conductivity region begins.

Figure 9. Frequency dependence of AC conductivity for all about potassium borates samples.

\section{Conclusion}

In the present study, effects of using various raw materials, reaction temperatures and reaction times on the liquid state synthesis of potassium borates were examined. Also, electrical and optical properties of synthesized of potassium borates were investigated. XRD results showed that Santite $\left(\mathrm{KB}_{5} \mathrm{O}_{8} \cdot 4 \mathrm{H}_{2} \mathrm{O}\right)$ was synthesized at all the experimental sets. FT-IR and Raman spectra of products had characteristic potassium borate peaks in both IR and visible regions. The DC electrical resistivities of synthesized potassium borate materials are in the range of $4.17 \times 10^{8}-4.07 \times 10^{10} \Omega . \mathrm{cm}$. The dielectric constants were frequency dependent and varied between $2 \times 10^{5}$ to $2 \times 10^{6}$ at low frequencies $\left(5-10^{2} \mathrm{~Hz}\right)$, and about 10 at high frequencies. It was determined that the AC conductivity of the material depends on the frequency of $10^{3} \mathrm{~Hz}$ sub-frequencies. In addition to the optical absorption edge of the potassium borate powders observed about $340 \mathrm{~nm}$ for SET 1 to 5 and about $480 \mathrm{~nm}$ for SET 6 .

\section{REFERENCES}

[1] T.R. Prime Ministry SPO, Chemical Industry Private Expertise Commission, Boron Operations Group Report: Ninth Development Plan (2007- 2013), Turkey (2006).

[2] R. Beatty, The Elements: Boron, Marshall Cavendish, New York, (2005).

[3] G. Yang, Z. Li, Y. Zhang, Chem. Eng. Process. 44, 1216 (2005).

[4] K. Thamizharasan, S.X. Jesu Raja, F.P. Xavier, P. Sagayaraj, J. Cryst. Growth 218, 323 (2000). 
[5] S. Merlino, F. Sartori, Contr. Mineral. Petrol. 27, 159 (1970).

[6] M.O. Asensio, M. Yildirim, F. T. Senberber, A. S. Kipcak, E. Moroydor Derun, Res. Chem. Intermed., 42, 4859 (2016).

[7] H.X. Zhang, J. Zhang, S. T. Zheng, G. Y. Yang, Cryst. Growth Des., 5, 157 (2005).

[8] C.G. Salentine, Inorg. Chem., 26, 128 (1987).

[9] Q. Wu, Acta Cryst., E67, i67 (2011).

[10] G.M. Wang, Y. Q. Sun, S. T. Zheng, G. Y. Yang, Z. Anorg. Allg. Chem., 632, 1586 (2006).

[11] Z.H. Liu, P. Li, L.Q. Li, Q.X. Jia, Thermochim. Acta, 454, 23 (2007).

[12] A. Alicilar, F. Ökenek, B. Kayran, M. Tutak, Journal of the Faculty of Engineering and Architecture of Gazi University, 30, 701 (2015).

[13] A.M. Abdel-Ghany, Ahmad S. Abu-Khadra, M.S. Sadeq, J. Non Cryst. Solids., 548, 120320 (2020).

[14] B. Lyu, H. Li, L. Jiang, W. Shan, C. Hu, A. Deng, Z. Ying, L. Wang, Y. Zhang, H. B. Bechtel, M. C. Martin, T. Taniguchi, K. Watanabe, W. Luo, F. Wang, Z. Shi, Nano Lett. 19, 1982 (2019).

[15] M.I. Sayyed, Y.S. Rammah, F. Laariedh, A.S. Abouhaswa, T.B. Badeche, J. Non Cryst. Solids., 527, $119731(2020)$.

[16] S. N. Mohammad, Electrical characteristics of thin film cubic boron nitride, Solid State Electron., 46, 203 (2002).

[17] T. Ibroska, A.S. Kipcak, S. Aydin Yuksel, E. M. Derun, S. Piskin, Turk. J. Chem., 39, 1025 (2015).

[18] J. Yongzhong, G. Shiyang, X. Shuping, L. Jun, Spectrochim.Acta A, 56, 1291 (2000).

[19] L. Jun, X. Shuping, G. Shiyang, Spectrochim. Acta A, 51, 519 (1995). 
Figures

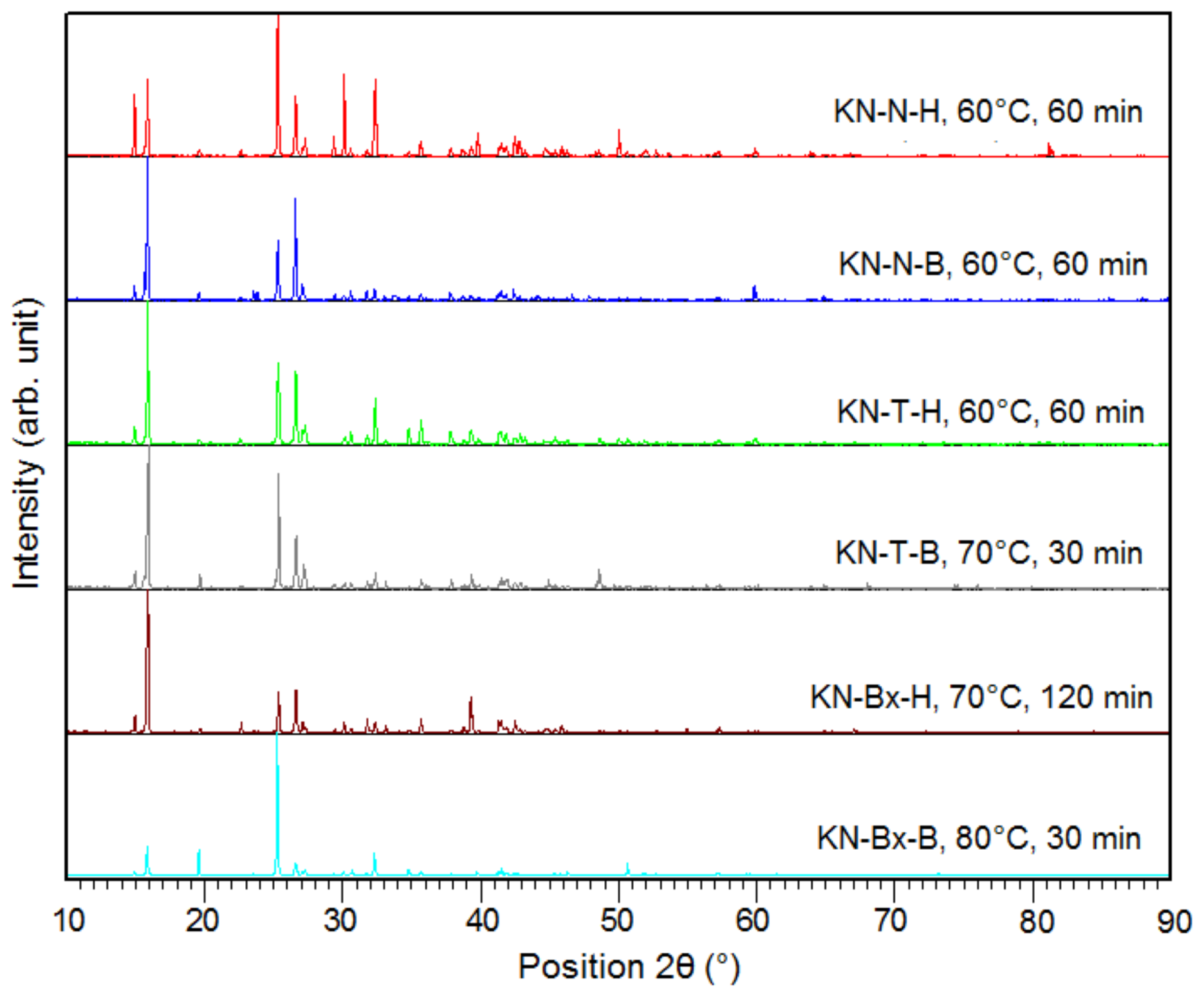

Figure 1

XRD patterns of the optimum potassium borate phases 


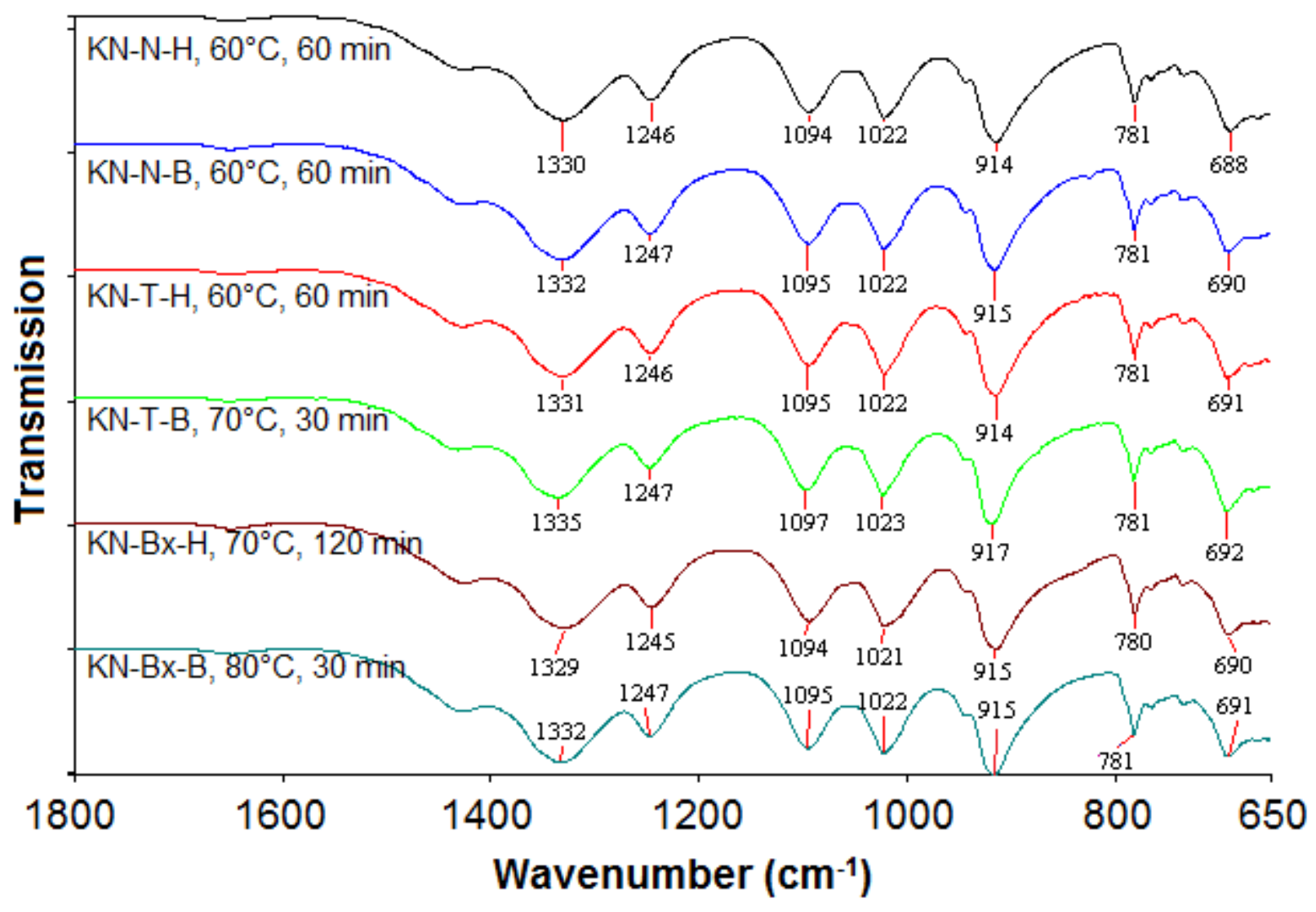

Figure 2

FT-IR spectra of selected potassium borates 


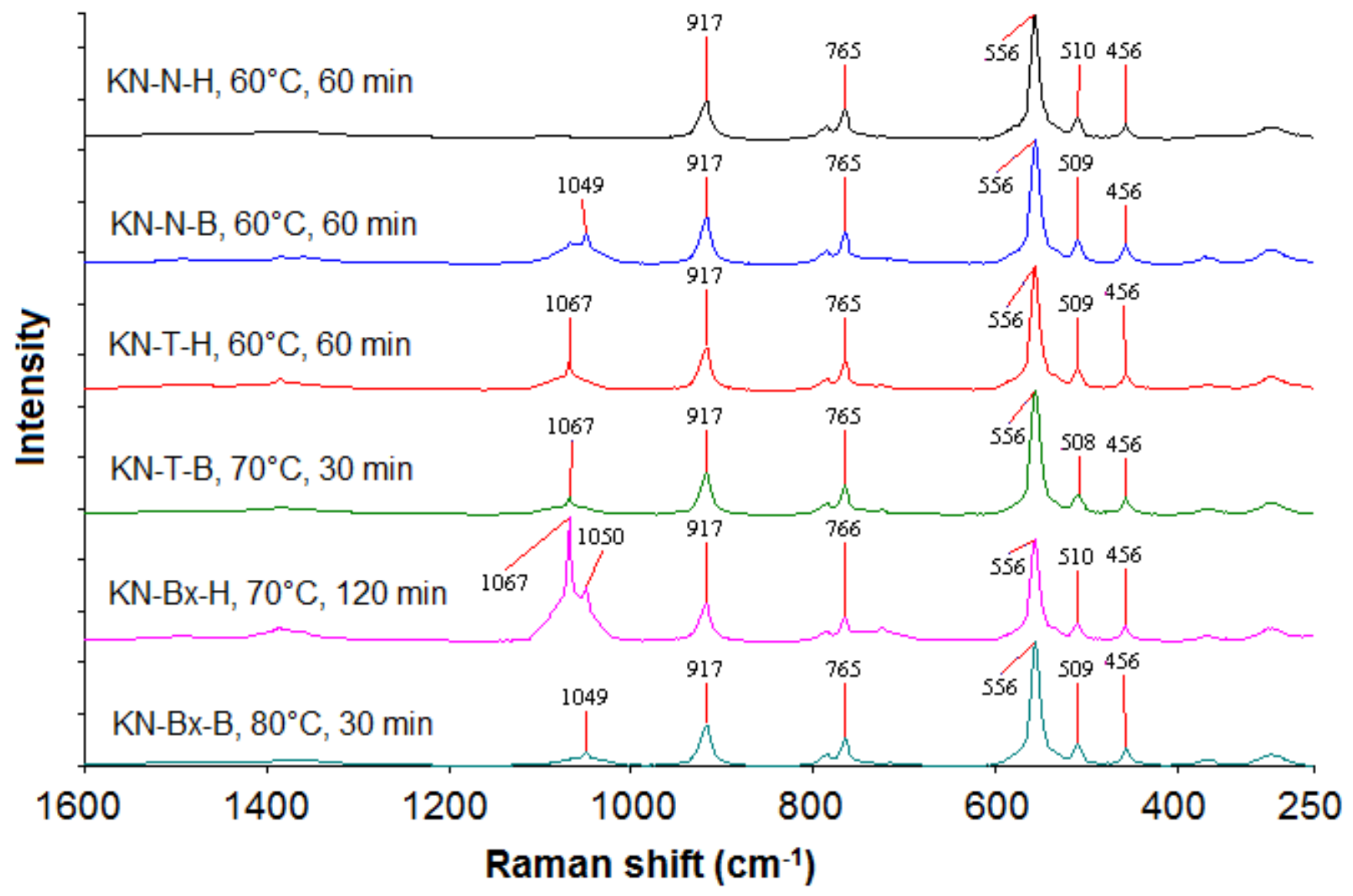

Figure 3

Raman spectra of selected potassium borates
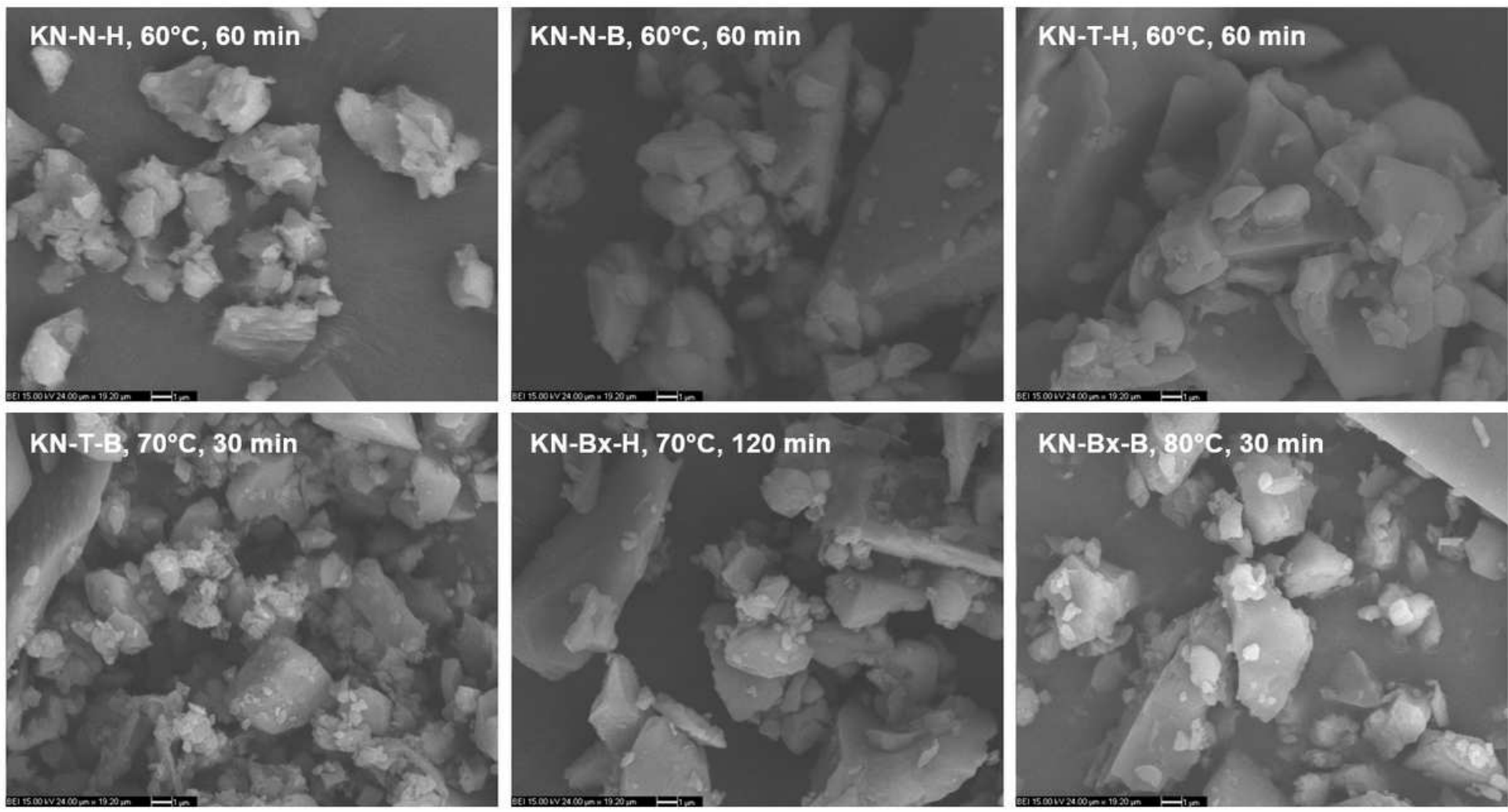


\section{Figure 4}

The surface morphologies of selected potassium borates
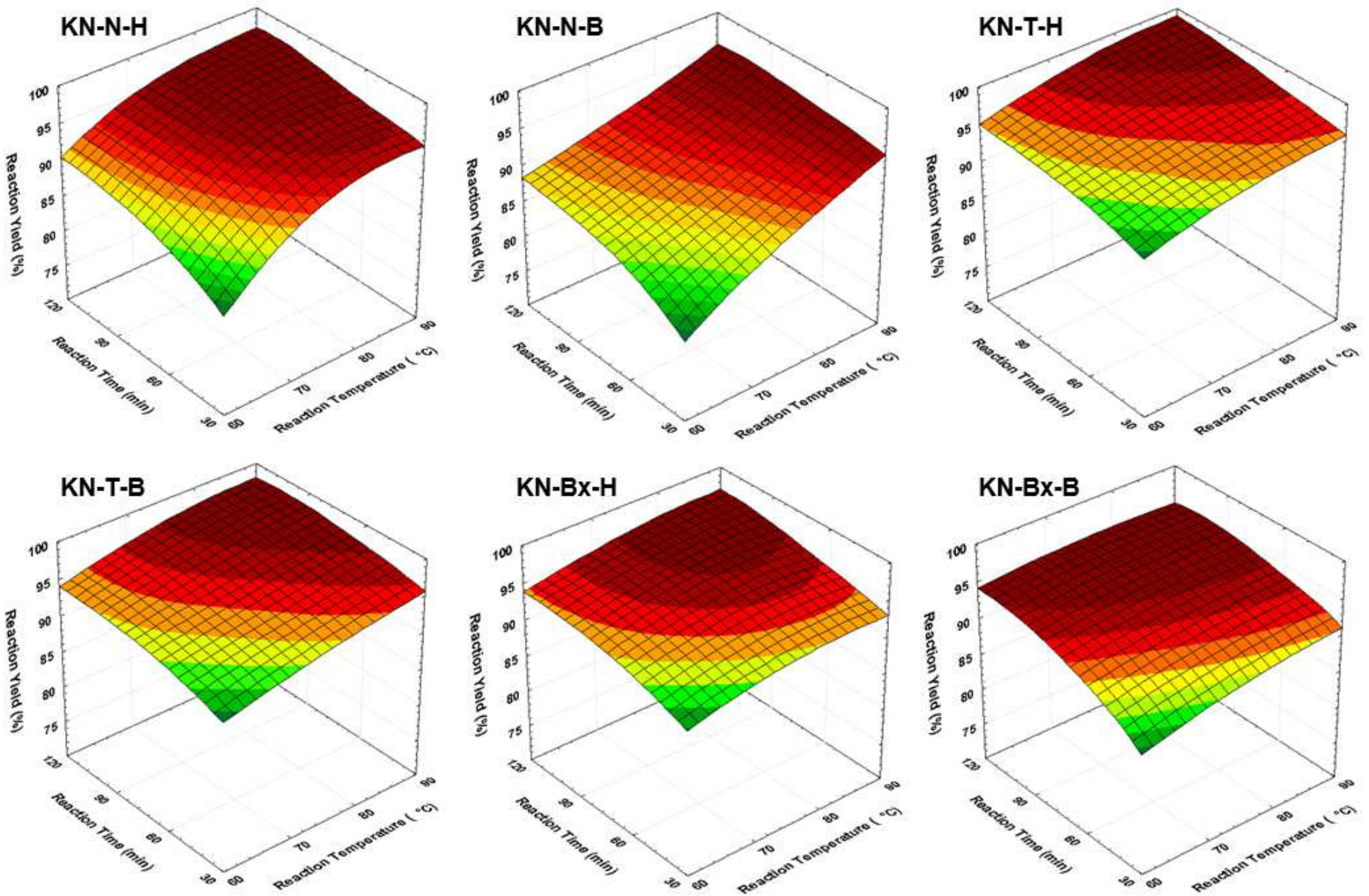

Figure 5

Reaction yields of samples 


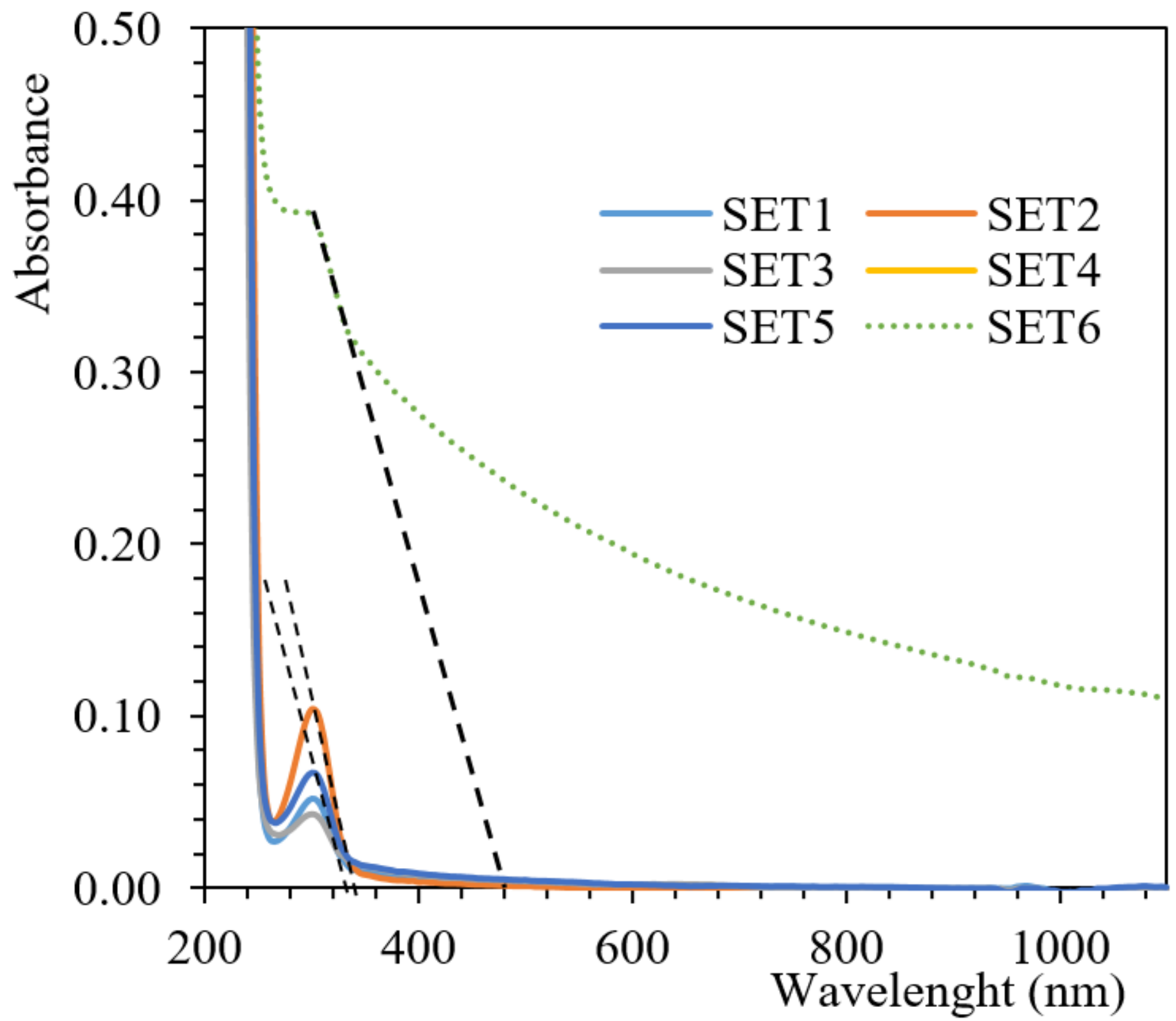

Figure 6

The optical absorbance spectrum of potassium borates powders. 


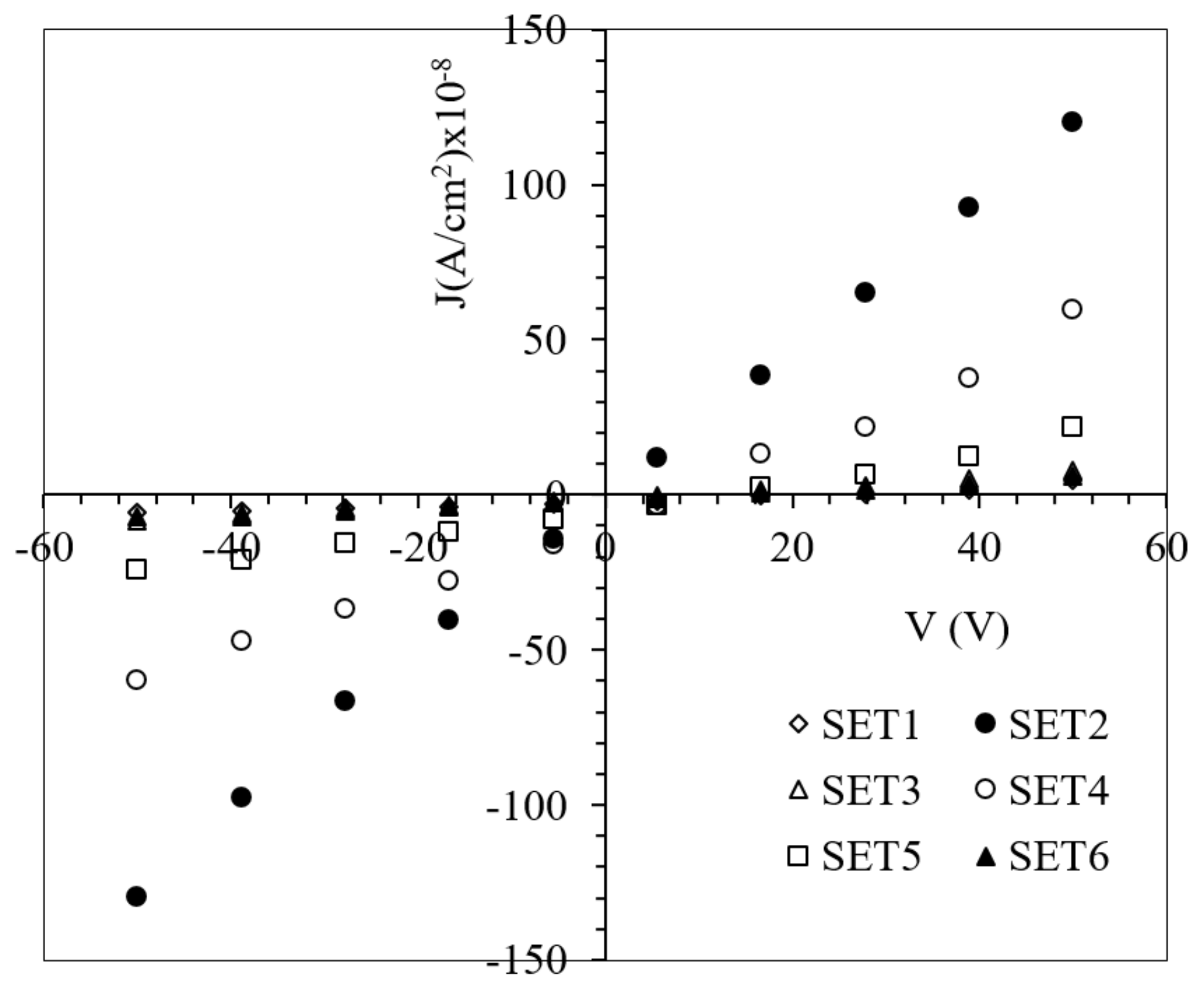

Figure 7

The DC current density-voltage characteristics of potassium borate materials synthesized using various boron minerals 


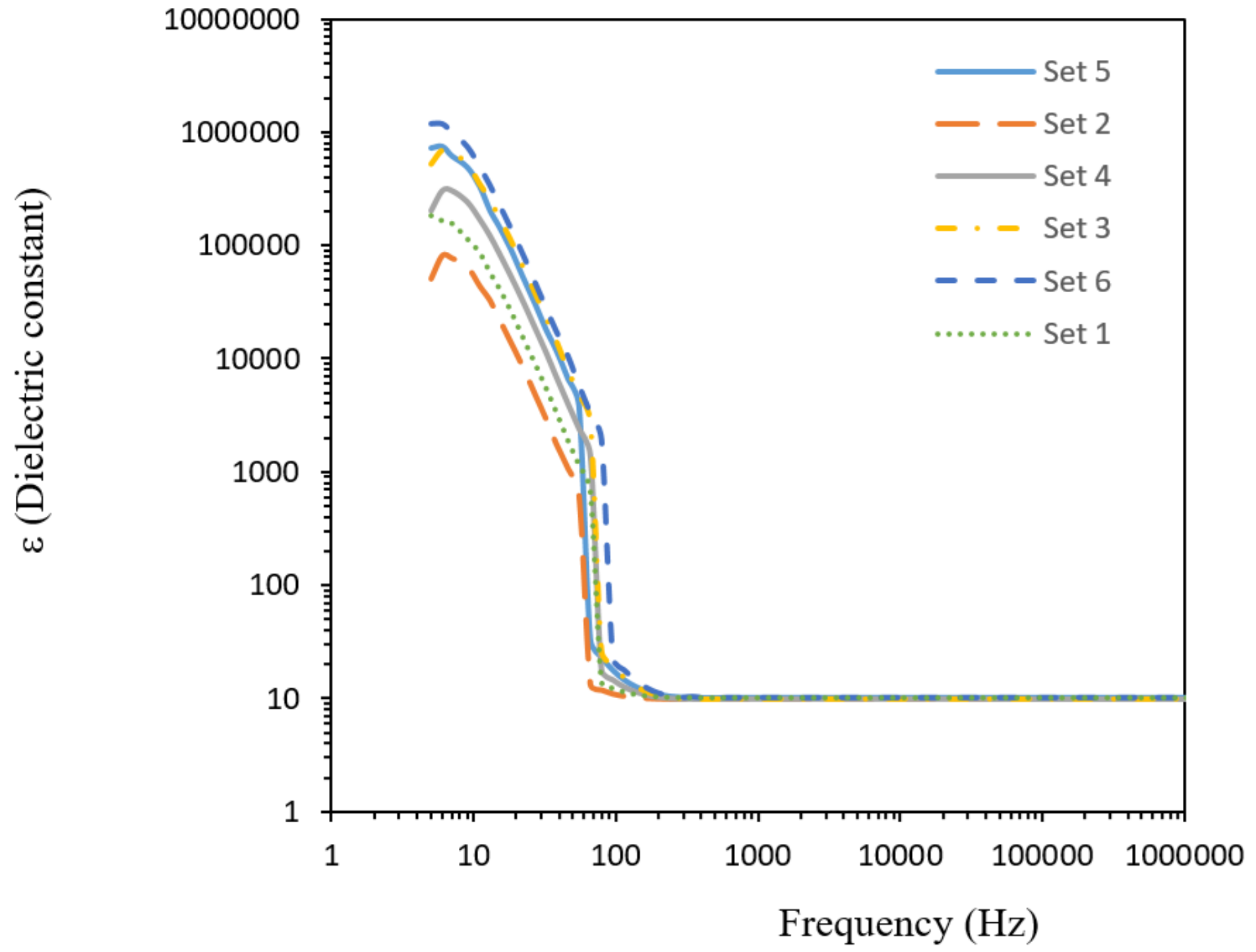

Figure 8

Frequency dependence of real part dielectric constant for potassium borates samples. 


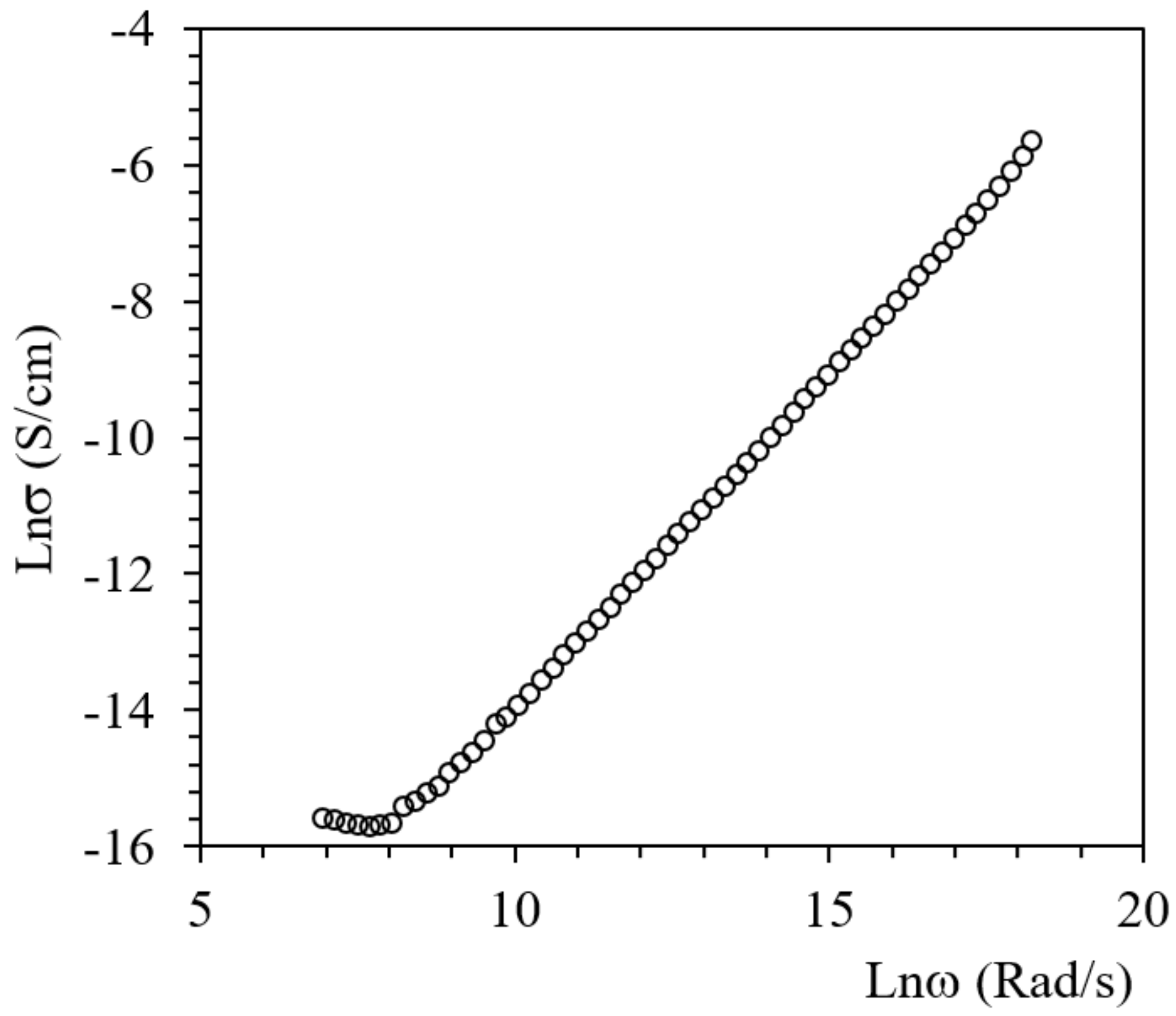

Figure 9

Frequency dependence of AC conductivity for all about potassium borates samples.

\section{Supplementary Files}

This is a list of supplementary files associated with this preprint. Click to download.

- GraphicalAbstract.docx 